\title{
Factors Associated with Poor Sleep Quality among Type 2 Diabetes Mellitus Patients on Insulin Therapy
}

\author{
Abilash Sathyanarayanan ${ }^{*}$, Elvin Benny2 ${ }^{2}$, Jenit Osborn ${ }^{3}$, Senthil Kumar ${ }^{4}$, \\ Suresh Prabhư ${ }^{4}$ Anil C. Mathew ${ }^{3}$ \\ ${ }^{1}$ PSG Institute of Medical Sciences and Research, Coimbatore, India \\ ${ }^{2}$ Department of Statistics, St. Thomas College, Pala, India \\ ${ }^{3}$ Department of Community Medicine, PSG Institute of Medical Sciences and Research, Coimbatore, India \\ ${ }^{4}$ Department of Endocrinology, PSG Institute of Medical Sciences and Research, Coimbatore, India \\ Email: ${ }^{\text {drabisat@gmail.com }}$
}

Received 8 June 2015; accepted 26 September 2015; published 29 September 2015

Copyright (C) 2015 by authors and Scientific Research Publishing Inc.

This work is licensed under the Creative Commons Attribution International License (CC BY).

http://creativecommons.org/licenses/by/4.0/

c) (i) Open Access

\begin{abstract}
The aim of this study is to investigate the possible risk factors of poor sleep quality among patients with type 2 diabetes mellitus on insulin therapy. The factors considered were age, sex, body mass index (BMI), glycosylated haemoglobin (HbA1c), duration of diabetes and depression. A total of 202 diabetic patients aged 20 years or older were included in the study. The results showed that female sex and depression were independent risk factors for poor sleep quality among type 2 diabetics on insulin therapy. Findings may contribute to sleep disorder control in female patients with type 2 diabetes mellitus which has been linked to glycemic control.
\end{abstract}

\section{Keywords}

Diabetes, Sleep Quality, Insulin Administration, Depression

\section{Introduction}

Diabetes is a major global public health problem. Rapid lifestyle changes have dramatically increased the prevalence of diabetes in recent years. Heart disease is noted in $68 \%$ of the death certificates in all deaths related to diabetes. Diabetes has also been attributed to be the leading cause of blindness and kidney failure [1]. The traditional interventional strategies including lifestyle changes such as weight loss, healthy eating, and increased physical

Corresponding author.

How to cite this paper: Sathyanarayanan, A., Benny, E., Osborn, J., Kumar, S., Prabhu, S. and Mathew, A.C. (2015) Factors Associated with Poor Sleep Quality among Type 2 Diabetes Mellitus Patients on Insulin Therapy. Journal of Diabetes Mellitus, 5, 206-210. http://dx.doi.org/10.4236/jdm.2015.54025 
activity are designed to prevent and manage diabetes and its complications. New strategies against the disease are needed. This is vital for the development of more efficient methods to counteract the progress of the disease and channelize our efforts directed at changes which most affect the disease. One component which is shown to have an impact is the relationship between diabetes and sleep quality [2]. Studies in other parts of the country have reported that short sleep duration or poor sleep quality may relate to glucose metabolism. Insulin administration was reported to be an important reason for the prevalence of sleep abnormalities. Data suggest that diabetes is associated with periodic breathing, a respiratory abnormality associated with abnormalities in the central control of ventilation, which in turn affects sleep [3].

This can have many ramifications over the course and treatment of the patients who are on chronic insulin therapy. Not many studies have examined the factors associated with poor sleep quality in patients with type 2 diabetes using insulin. A recent study was conducted including 140 type 2 diabetics on insulin therapy. The possible risk factors that were considered in the study were age, sex, BMI, HbAlc, duration of diabetes and global PSQI score [4]. The results of the study showed poor sleep quality in females type 2 diabetes patients with insulin therapy. However, in this study depression was not considered which might confound the findings. In addition, many studies have reported a higher prevalence of depression among patients on insulin therapy [5]-[7]. The aim of the present study is to examine the factors associated with poor sleep quality among type 2 diabetes on insulin therapy. The factors considered were age, sex, BMI, HbAlc, duration of diabetes and depression.

\section{Materials and Methods}

\subsection{Study Design}

A total of 202 diabetic patients aged 20 years or older who attended the endocrinology outpatient department at PSGIMSR in the month of July 2013 were studied. 71 were on insulin therapy. An interview was conducted in a separate room. Poor sleep quality measured using validated Pittsburgh Sleep Quality Index. The PSQI was created after observation that most patients with psychiatric disorders also have sleep disorders. The questionnaire has nineteen individual items which were used to generate seven composite scores. The results include seven categories: subjective sleep quality, sleep latency, sleep duration, habitual sleep efficiency, sleep disturbances, use of sleeping medication, and daytime dysfunction. The assessment took about five to ten minutes to administer and score. The patient is responsible for answering the questions from his or her subjective experience over the previous month. There is no machine evaluation of response time or sleepiness. A total PSQI score more than 5 was considered poor sleep quality. Depression was measured using the validated Center for Epidemiological Studies Depression (CESD) Scale [8] [9]. The CESD scale is a short self-report scale designed to measure depressive symptomatology in the general population. The items of the scale are symptoms associated with depression which have been used in previously validated longer scales. It was found to have very high internal consistency and adequate test-retest repeatability. The scale is a useful tool for epidemiologic studies of depression. Subjects who scored more than 16 out of 60 points on the CESD scale were classified as having elevated depressive symptoms. Obesity was defined as BMI $>30 \mathrm{~kg} / \mathrm{m}^{2}$. The $\mathrm{HbAlc}$ values were determined by high performance liquid chromatography. Patients with GDM/Renal replacement therapy/malignancies/liver cirrhosis were excluded. The study got approval from Institution Human Ethics committee.

\subsection{Statistical Analysis}

The data were analysed using SPSS (19.Version). t-test was used to compare the means of the quantitative variables. Chi square to test was used to compare proportions. Multivariate logistic regression analysis was used to compare the factors associated with poor sleep quality. P value less than 0.05 was considered as statistically significant.

\section{Results}

It is observed that out of the 71 patients on insulin therapy, 27 were females and 44 patients were males. Of the females, 16 reported a poor sleep quality and among males 15 reported poor sleep quality. The percentage of females were higher $51.6 \%$ among those who reported poor sleep quality compared with those having good sleep quality $(27.5 \%)$ and the difference was statistically significant $(p<0.05)$. The mean (SD) of duration of diabetes 
(years) were significantly higher $(p<0.05)$ among those having poor sleep quality $14.81(8.86)$ when compared with those having good sleep quality 10.43 (7.68). The mean CESD score was higher $(p<0.001)$ among those having poor sleep quality 23.74 (8.57) compared with those having good sleep quality 17.02 (4.28). No significant difference was observed with regard to age, BMI, and HbAlc between those having poor sleep quality and good sleep quality. The findings are presented in Table 1 . In the multivariate logistic regression analysis, it was observed that Sex and Depression were independent risk factors for poor sleep quality among type 2 diabetes on insulin therapy (Table 2).

\section{Discussion}

India is known as the diabetes capital of the world. More than $80 \%$ of diabetes deaths occur in low- and middleincome countries. WHO projects that diabetes will be the 7th leading cause of death in 2030 [1]. There are complex and interacting factors which affect the control of the quality of sleep in patients with diabetes, and they exert a greater impact on the glycemic control of these patients.

Based on the results obtained, we observed that sex is an independent risk factor for poor sleep quality among those with type 2 diabetes mellitus on insulin therapy. It has been revealed in previous studies that the female sex might have an influence on the number of hours and the quality of sleep a person gets. Our results further validate these findings by showing similar results. The mechanism by which sex may influence the prevalence of sleep quality is still unknown. Previous studies have shown that the PPAR-GAMMA receptor might influence this value, but there are no confirming studies which prove this [10]-[12]. In a developing country like India, where a majority of the population is agriculture dependent, strict gender stereotypes are prevalent and it is important to address the fact that the female population may be unfairly affected by poor sleep quality, which may further translate to having a poorer glycemic control. This being a cross sectional study, we are not be able to infer the direction of association. The factors that contribute to this poor sleep quality among the female diabetics have to be further evaluated by studies and those results might prove valuable to the management of the disease effectively in this sector of the population.

Table 1. Clinical characteristics of 71 patients with type 2 diabetes on insulin therapy.

\begin{tabular}{|c|c|c|c|c|}
\hline Characteristics & $\begin{array}{l}\text { Poor quality sleep mean (SD) } \\
\qquad \mathbf{N}=\mathbf{3 1}\end{array}$ & $\begin{array}{l}\text { Good quality sleep mean (SD) } \\
\qquad \mathbf{N}=\mathbf{4 0}\end{array}$ & t value & $p$ value \\
\hline Age & $56.55(9.62)$ & $53.28(8.58)$ & 1.51 & 0.135 \\
\hline BMI & $26.45(4.82)$ & $25.54(3.71)$ & 0.90 & 0.371 \\
\hline HbA1c & $9.64(2.00)$ & $9.51(2.23)$ & 0.26 & 0.795 \\
\hline Duration of diabetes (years) & $14.81(8.86)$ & $10.43(7.68)$ & 2.22 & $p<0.05$ \\
\hline CES D score & $23.74(8.57)$ & $17.02(4.28)$ & 4.311 & $p<0.001$ \\
\hline Sex female $(\%)$ & $16(51.6)$ & $11(27.5)$ & $\mathrm{X}^{2}=4.30$ & $p<0.05$ \\
\hline
\end{tabular}

Table 2. Results of multivariate logistic regression analysis of the association between clinical characteristics and disturbed subjective sleep.

\begin{tabular}{|c|c|c|c|}
\hline Variable & Odds ratio & $95 \% \mathrm{CI}$ & $p$ value \\
\hline Age & 1.035 & $0.96-1.11$ & 0.350 \\
\hline Sex & 4.058 & $1.05-15.63$ & $p<0.05$ \\
\hline \multicolumn{3}{|l|}{ Female } & \\
\hline BMI & 0.934 & $0.80-1.08$ & 0.364 \\
\hline Duration of diabetes & 1.042 & $0.96-1.12$ & 0.26 \\
\hline Depression CESD score & 6.42 & $1.65-24.88$ & $p<0.001$ \\
\hline
\end{tabular}


The results also revealed that depression can act as an independent risk factor for poor sleep quality. Many studies have reported that patients with depression tend to experience sleep disruption. Unipolar depression has been attributed to cause sleep quality disruption due to many factors [13]. It has been shown that troubled or fragmented sleep patterns are hallmarks of mood disorders, especially depression [14]. At least $80 \%$ of depressed people experience insomnia - difficulty falling asleep or most often, staying asleep [15] [16]. Early morning awakenings are a very characteristic feature of depression and they may also have problems associated with poor sleep quality like day time sleepiness, headache, apnoeic spells, obesity and predispositions to a variety of other morbid illnesses of which the most important remain hypertension and diabetes [15] [16]. Disturbed sleep and nocturnal altered breathing are related to disturbances of glucose metabolism. Many studies have explored the role of these factors on the variability of fasting glycemia [17] [18]. They have revealed that the respiratory and sleep disturbances that are seen due to a variety of factors have a very direct influencing effect on the glycemic control of a patient. Studies have shown positive correlation between the sleeping pattern and the glycemic control. Erratic variations on the sleep schedules of both humans and other animals have shown that they have an adverse influence on the fasting blood glucose levels [19] [20]. Among patients on insulin therapy it is seen that patients who have a higher CESD score are more prone of sleep disturbances, this is in keeping with the other studies. People who are on insulin therapy have a more malignant form of the disease and thus are subjected to a greater amount of medical scrutiny, stricter treatment protocols and guidelines [21]. They are also more likely to have other comorbidities and a greater pressure of maintaining a narrower glycemic level [22]. Most patients are on concurrent medications which might further drive the erratic variations in glucose levels [23]. These factors may also be responsible for the depression in these patients. Since this is a small cross sectional study and we are unable to evaluate the causal relationship.

In our study obesity was not significantly associated with sleep quality. Some studies proved that obesity was correlated with insulin resistance in diabetics, and that insulin resistance is significantly correlated with sleep quality [24]. There are other limitations to this study. We used a questionnaire to evaluate sleep quality rather than performing polysomnography, thus it is a more subjective interpretation of the sleep disturbance. Objective measures have a higher value in establishing a connection between these factors. We did not record the number of insulin doses per day, the dosage of oral diabetic agents and the prevalence of nocturnal hypoglycaemia. Thus the pattern of drug usage may cause variations in the sleep patterns of these patients. This limitation has to be addressed by further studies.

\section{Conclusion}

The prevalence of sleep disorders was particularly higher in women. Female patients with type 2 diabetes are more likely to develop subjective sleep disorders during insulin therapy than males. Depression is also prevalent in this vulnerable sector of the population. And both these factors influence the glycemic control. Thus, it becomes vital to further reveal the connections among these factors, the lifestyle habits and other influences attributed to them. This may extend the scope of treatment of diabetics in the future to not only the glycemic control but a holistic approach to addressing their various other concerns which may have a direct bearing on the long-term treatment prognosis and outcome. Thus, more studies are needed to examine the nature of sleep disturbances in patients with type 2 diabetes on insulin therapy particularly among women.

\section{References}

[1] WHO Diabetes - Facts and Statistics. http://www.who.int/mediacentre/factsheets/fs312/en/

[2] Koren, D., O’Sullivan, K.L. and Mokhlesi, B. (2015) Metabolic and Glycemic Sequelae of Sleep Disturbances in Children and Adults. Current Diabetes Reports, 15, 562. http://dx.doi.org/10.1007/s11892-014-0562-5

[3] Resnick, H.E., Redline, S., Shahar, E., Gilpin, A., Newman, A., Walter, R., Ewy, G.A., Howard, B.V. and Punjabi, N.M. (2003) Diabetes and Sleep Disturbances Findings from the Sleep Heart Health Study. Diabetes Care, 26, 702709.

[4] Song, Y., Ye, X., Ye, L., Li, B., Wang, L. and Hua, Y. (2013) Disturbed Subjective Sleep in Chinese Females with Type 2 Diabetes on Insulin Therapy. PLoS ONE, 8, e54951. http://dx.doi.org/10.1371/journal.pone.0054951

[5] Cappuccio, F.P., et al. (2010) Sleep Duration and All-Cause Mortality: A Systematic Review and Meta-Analysis of Prospective Studies. Sleep, 33, 585.

[6] Culebras, A. (2008) Sleep Disorders. In: Heggenhougen, K. and Quah, S., Eds., International Encyclopedia of Public 
Health, Vol. 6, Academic Press, San Diego, 21-26. http://dx.doi.org/10.1016/B978-012373960-5.00031-9

[7] Tamminen, J., Payne, J.D., Stickgold, R., Wamsley, E.J. and Gareth Gaskell, M. (2010) Sleep Spindle Activity Is Associated with the Integration of New Memories and Existing Knowledge. The Journal of Neuroscience, 30, Article ID: 14356. http://dx.doi.org/10.1523/JNEUROSCI.3028-10.2010

[8] Radloff, L.S. (1977) The CES-D Scale: A Self-Report Depression Scale for Research in the General Population. Applied Psychological Measurement, 1, 385-401.

[9] Buysse, D.J., Reynolds 3rd, C.F., Monk, T.H., Berman, S.R. and Kupfer, D.J. (1989) The Pittsburgh Sleep Quality Index: A New Instrument for Psychiatric Practice and Research. Psychiatry Research, 28, 193-213. http://dx.doi.org/10.1016/0165-1781(89)90047-4

[10] Kavalkova, P., Touskova, V., Roubicek, T., Trachta, P., Urbanova, M., Drapalova, J., Haluzikova, D., Mraz, M., Novak D, Matoulek, M., Lacinova, Z. and Haluzik, M. (2013) Serum Preadipocyte Factor-1 Concentrations in Females with Obesity and Type 2 Diabetes Mellitus: The Influence of Very Low Calorie Diet, Acute Hyperinsulinemia, and Fenofibrate Treatment. Hormone and Metabolic Research, 45, 820-826. http://dx.doi.org/10.1055/s-0033-1353210

[11] Nadal-Casellas, A., Proenza, A.M., Lladó, I. and Gianotti, M. (2012) Sex-Dependent Differences in Rat Hepatic Lipid Accumulation and Insulin Sensitivity in Response to Diet-Induced Obesity. Biochemistry and Cell Biology, 90, 164172. http://dx.doi.org/10.1139/o11-069

[12] Dunn, S.E., Ousman, S.S., Sobel, R.A., Zuniga, L., Baranzini, S.E., Youssef, S., Crowell, A., Loh, J., Oksenberg, J. and Steinman, L. (2007) Peroxisome Proliferator-Activated Receptor (PPAR)alpha Expression in T Cells Mediates Gender Differences in Development of T Cell-Mediated Autoimmunity. The Journal of Experimental Medicine, 204, 321-330.

[13] Bratis, D., Spanopoulou, A., Dumitru, S., Lagou, S., Diamandi, C., Tselebis, A., Moussas, G., Karkanias, A., Gyftopoulos, S. and Kosmas, E. (2010) Sleep Disturbance Symptoms and Their Associations with Alexithymia, Depression and Anxiety. Ann Gen Psychiatry. Annals of General Psychiatry, 9, S163. http://dx.doi.org/10.1186/1744-859x-9-s1-s163

[14] Marinova, P., Koychev, I., Laleva, L., Kancheva, L., Tsvetkov, M., Bilyukov, R., Vandeva, D., Felthouse, A. and Koychev, G. (2014) Nightmares and Suicide: Predicting Risk in Depression. Psychiatria Danubina, 26, 159-164.

[15] Robillard, R., Hermens, D.F., Naismith, S.L., White, D., Rogers, N.L., Ip, T.K., Mullin, S.J., Alvares, G.A., Guastella, A.J., Smith, K.L., Rong, Y., Whitwell, B., Southan, J., Glozier, N., Scott, E.M. and Hickie, I.B. (2014) Ambulatory Sleep-Wake Patterns and Variability in Young People with Emerging Mental Disorders. Journal of Psychiatry \& Neuroscience, 39, Article ID: 130247.

[16] Itani, O., Kaneita, Y., Ikeda, M., Kondo, S., Yamamoto, R., Osaki, Y., Kanda, H., Suzuki, K., Higuchi, S. and Ohida, T. (2013) Disorders of Arousal and Sleep-Related Bruxism among Japanese Adolescents: A Nationwide Representative Survey. Sleep Medicine, 14, 532-541. http://dx.doi.org/10.1016/j.sleep.2013.03.005

[17] Labarca, G., Cruz, N.R. and Descalzi, F. (2014) Multisystemic Involvement in Obstructive Sleep Apnea. Revista médica de Chile, 142, 748-757. http://dx.doi.org/10.4067/S0034-98872014000600009

[18] Xu, T., Feng, Y., Peng, H., Guo, D. and Li, T. (2014) Obstructive Sleep Apnea and the Risk of Perinatal Outcomes: A Meta-Analysis of Cohort Studies. Scientific Reports, 4, 6982. http://dx.doi.org/10.1038/srep06982

[19] Kadono, M. and Hasegawa, G. (2014) Insomnia Disorder Comorbid with Diabetes. Nippon Rinsho, 72, 977-982.

[20] Okubo, N., Matsuzaka, M., Takahashi, I., Sawada, K., Sato, S., Akimoto, N., Umeda, T. and Nakaji, S., Hirosaki University Graduate School of Medicine (2014) Relationship between Self-Reported Sleep Quality and Metabolic Syndrome in General Population. BMC Public Health, 14, 562. http://dx.doi.org/10.1186/1471-2458-14-562

[21] Liou, D.Z., Singer, M.B., Barmparas, G., Harada, M.Y., Mirocha, J., Bukur, M., Salim, A. and Ley, E.J. (2015) Insulin-Dependent Diabetes and Serious Trauma. European Journal of Trauma and Emergency Surgery, In Press.

[22] Ganz, M.L., Li, Q., Wintfeld, N.S., Lee, Y.C., Sorli, C. and Huang, J.C. (2015) The Dynamic Relationship between Current and Previous Severe Hypoglycemic Events: A Lagged Dependent Variable Analysis among Patients with Type 2 Diabetes Who Have Initiated Basal Insulin. Current Medical Research and Opinion, 31, 1809-1815.

[23] Bramlage, P., Gitt, A.K., Binz, C., Krekler, M., Deeg, E. and Tschöpe, D. (2012) Oral Antidiabetic Treatment in Type2 Diabetes in the Elderly: Balancing the Need for Glucose Control and the Risk of Hypoglycemia. Cardiovascular Diabetology, 11, 122. http://dx.doi.org/10.1186/1475-2840-11-122

[24] Liu, A., Cardell, J., Ariel, D., Lamendola, C., Abbasi, F., Kim, S.H., Holmes, T.H., Tomasso, V., Mojaddidi, H., Grove, K., Kushida, C.A. and Reaven, G.M. (2015) Abnormalities of Lipoprotein Concentrations in Obstructive Sleep Apnea Are Related to Insulin Resistance. Sleep, 38, 793-799. 